
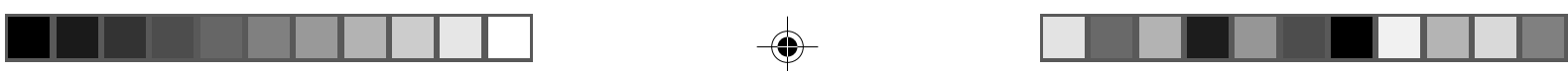

\title{
A contribuição de Alexandre Rodrigues Ferreira para a formação do pensamento social na Amazônia
}

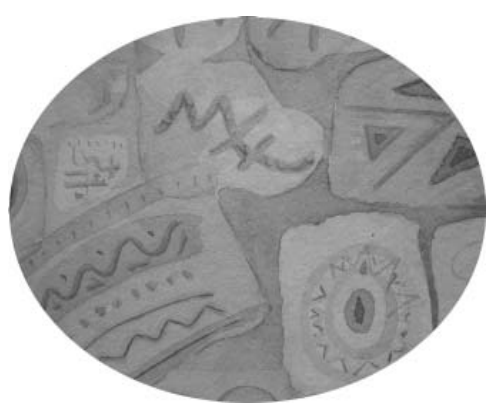

JoséNailton Leite*

Cecilia Sayonara G. Leite**

\section{Resumo}

O presente trabalho estabelece o tratamento de conceitos-chave e termos relevantes para a compreensão da expedição filosófica chefiada por Alexandre Rodrigues Ferreira no século XVIII. Tem o propósito de mostrar ao leitor um pouco da biografia do autor. Propõe uma reflexão antropológica sobre os povos da América descobertos durante a viagem que durou quase dez anos. A análise aponta para a relação comparativa entre os povos do Novo Mundo e os do velho continente, destacando o choque cultural entre eles como aspecto relevante para o desmoronamento do eurocentrismo. O trabalho pretende, em especial, demonstrar a contribuição de Alexandre Rodrigues Ferreira para a formação do pensamento social da Amazônia.

Palavras-chave: História natural. Alexandre Rodrigues Ferreira. Século XVIII. Amazônia. Expedições científicas. Antropologia.

\section{Abstract}

This work establishes the treatment of key concepts and relevant terms to the comprehension of the philosophical expedition led by Alexandre Rodrigues Ferreira

\footnotetext{
Mestre em Sociedade e Cultura na Amazônia pela Universidade Federal do Amazonas (Ufam) e professor efetivo da Universidade Federal de Rondônia (Unir). @ - nailton@unir.br

** Mestre em Sociedade e Cultura na Amazônia pela Universidade Federal do Amazonas (Ufam) e professora do Centro Universitário do Norte (Uninorte). @ - sayonaragonzaga@hotmail.com
} 
in the 18th century. Its purpose is to show a little of the writer's biography to the reader. It suggests an anthropological reflection on the American people discovered during a nearly 10 -year journey. The analysis indicates the comparative relation between these groups of people from the new and the old world, highlighting the cultural clash between them as a relevant aspect to the collapse of Eurocentrism. The main purpose of this work is to demonstrate the contribution by Alexandre Rodrigues Ferreira to the social thinking on the Amazônia.

Keywords: Natural history. Alexandre Rodrigues Ferreira. 18th Century. Amazônia. Scientific expeditions. Anthropology.

Alexandre Rodrigues Ferreira nasceu no Brasil, na cidade de Salvador, em 27 de abril de 1756 (Prestes, 2000), mas foi educado em Portugal. Em 1770, aos quatorze anos de idade, matriculou-se na Faculdade de Medicina da Universidade de Coimbra onde permaneceu por dois anos. Em seguida, transferiu-se para a Faculdade de Filosofia, na qual, em 1778, obteve sua titulação em Filosofia Natural (ibidem). Caracterizado por um perfil multitemático em suas investigações, foi denominado zoólogo, geógrafo, sociólogo, etnólogo, antropólogo, economista e agrônomo, pelos diversos autores que escreveram sua biografia. Apesar de não concluir o curso de Medicina, escreveu a monografia Enfermidades endêmicas da Capitania de Mato Grosso contribuindo para a temática médica, sendo mesmo chamado de "médico" baiano (ibidem).

Aos 27 anos, recém-egresso da Universidade de Coimbra, foi indicado por Domingos Vandelli ${ }^{1}$ para chefiar uma expedição filosófica ${ }^{2}$ organizada, dirigida e financiada pelo Estado lusitano (COSTA, 2001). Alexandre seguiu imediatamente para Lisboa; entretanto, esperou cinco anos para o início da expedição. Nesse intervalo se envolveu em atividades relacionadas à História natural que lhe renderam a eleição como membro da Real Academia das Ciências de Lisboa (PRESTES, 2000). Em 1783, finalmente, Ferreira partiu para a expedição, considerada o evento de cunho científico mais importante empreendido por Portugal em solo brasileiro.

A expedição chefiada por ele, na qualidade de naturalista, estendeu-se pelas capitanias do Grão-Pará, São José do Rio Negro (Amazonas) e Mato Grosso (Cuiabá). Durante a viagem, Ferreira deveria estudar a etnografia das regiões percorridas, relatar e acondicionar os produtos encontrados e cuidar dos aspectos práticos da expedi-

40 Somanlu, ano 9, n. 1, jan./jun. 2009 


\section{Viagem filosófica pelas capitanias do Grão-Pará, Rio Negro, Mato Grosso e Cuiabá}

A obra de Alexandre Rodrigues Ferreira representa uma preciosa e completa fonte de informação para o acesso à visão da Amazônia do século XVIII. Traz contribuições para os diversos campos da pesquisa, desde a história política até a história do cotidiano, faz uma detalhada descrição das riquezas existentes na Amazônia, além de uma importante referência etnológica ao descrever e comparar os povos do Novo Mundo com os europeus. Sem dúvida, afirma Costa (2001), as grandes viagens marítimas anteriores à expedição de Alexandre Rodrigues Ferreira trouxeram grande avanço para ampliação do conhecimento sobre a geografia dos continentes, agrega- 
ram inúmeras informações acerca dos reinos animal, vegetal e mineral, bem como contribuíram para desfazer mitos e descobrir povos com novas culturas. Porém, não foram suficientes para desvendar as terras interiores. Nesse sentido, Humboldt (apud COSTA, 2001) afirma que só é possível conhecer verdadeiramente um lugar quando se penetra seu interior, pois é justamente aí que consiste a possibilidade de conhecer sua fauna, flora, a composição do solo e, especialmente, os povos que o habitam. O continente americano não era uma exceção, e a exploração de parte do território amazônico, da capitania de Mato Grosso e Cuiabá fazia parte do acordo contido nos tratados assinados entre Portugal e Espanha.

Por força desses tratados (que definiam suas fronteiras com base na ocupação efetiva) firmados entre as duas colônias ibéricas, a expedição filosófica chefiada por Alexandre Rodrigues Ferreira foi idealizada, em 1778, por Martinho de Melo e Castro, ministro da Secretaria dos Negócios da Marinha e Domínios Ultramarinos, com o intuito de agregar o interesse científico e econômico ao caráter político-militar das comissões de demarcação (COSTA, 2001; PRESTES, 2000). Conforme Prestes (2000), apesar de se propor à expansão das ciências, a expedição não possuía um caráter exclusivamente científico. O evento não se encarregaria somente de pesquisar a fauna, a flora e os minerais do Brasil. Vale ressaltar que ele também deveria responder a outro propósito: o de recolher uma variada gama de informações de ordem socioeconômica e política. À época da expedição, assinalam Galvão e Moreira Neto (1974), Portugal havia exaurido a produção de ouro e diamantes do Brasil. Nessa ocasião, a metrópole redirecionava seus interesses para a agricultura brasileira, a qual se mostrava muito promissora. Prestes (2000) afirma que a Coroa portuguesa buscava desesperadamente encontrar ao mesmo tempo as causas e as soluções para o atraso e a decadência de suas atividades econômicas, mesmo que isso significasse permanecer muito aquém de outros países europeus no avanço da ciência. De fato, a Coroa portuguesa ainda esperaria muito tempo para esse feito.

Nesse cenário, Alexandre Rodrigues Ferreira aceitara uma grande empreitada que era a de estudar a natureza amazônica: encontrar uma forma de a exploração empreendida por sua expedição ser lucrativa para Portugal. Como o aspecto econômico não interessava aos avanços do conhecimento almejado pelo século das Luzes, é possível que o próprio Ferreira tenha contribuído para que sua expedição não fosse devidamente reconhecida como um evento de cunho científico.

42 Somanlu, ano 9, n. 1, jan./jun. 2009 




Além de se propor ao avanço da ciência, a expedição demonstrava a grande visão estratégica portuguesa no final do século XVIII, pois o território brasileiro estava contido num projeto estatal com a finalidade de estudar a natureza segundo os critérios da História Natural. Dessa forma, seria possível uma descrição geográfica exata de cada lugar que possibilitava a exploração racional dos territórios coloniais (COSTA, 2001). A expedição filosófica de Alexandre Rodrigues Ferreira nos rendeu um inestimável conjunto de informações sobre a fauna, a flora, os minérios, herbários, animais empalhados, amostras de madeira, desenhos e aquarelas, e uma rica análise etnográfica das populações indígenas. No entanto, vários teóricos especialistas no assunto demonstram em seus textos que grande parte do material coletado pelo autor foi extraviado no transporte para Portugal ou saqueado, como o saque feito pelos franceses sob as ordens do marechal Junot, em 1808. Ferreira estaria incumbido de percorrer 39 mil quilômetros de hileia e sertão observando, registrando e colecionando tudo o que encontrasse. Deveria, ainda, obedecer à árdua tarefa do conjunto de instruções burocráticas determinadas pelo governador e capitão-general do Estado, Martinho de Souza de Albuquerque. A expedição durou quase dez anos; as narrativas de Alexandre Rodrigues Ferreira falaram de encontros, cenários e personagens. Em suas memórias e seus diários, registravam-se dificuldades, sucessos e fracassos. As cartas enviadas às autoridades portuguesas por Ferreira constatam esse fato quando ele fala das constantes deserções pelos soldados e índios domésticos. ${ }^{4}$

A primeira fase da passagem de Alexandre Rodrigues Ferreira pela Amazônia brasileira se deu nas capitanias do Grão-Pará e Rio Negro, onde passou a maior parte do tempo da viagem e durante o qual coletou um riquíssimo acervo e registrou suas descobertas em diários e memórias. A segunda se deu na capitania de Mato Grosso e Cuiabá, num trajeto entre os rios Madeira, Mamoré e Guaporé até os confins das terras lusitanas. A capitania de Mato Grosso e Cuiabá era pouco conhecida e estudada, mas era um grande atrativo para Portugal, pois era recém-ocupada pelos espanhóis, limite com o vice-reino do Peru, e rica em ouro e diamantes.

No que concerne aos relatos do cotidiano, registros em diários e quantidade de desenhos e aquarelas, percebe-se que a primeira etapa da viagem é vastamente documentada, enquanto a segunda, ou seja, a passagem por Mato Grosso, é pouco 
explorada e conhecida. Com efeito, apesar de menos documentada, o conjunto de informações deixado por Rodrigues Ferreira é o bastante para afirmar que a viagem pela capitania de Mato Grosso e Cuiabá foi suficiente para o reconhecimento das fronteiras com os territórios castelhanos e as questões referentes à mineralogia. $\mathrm{Na}$ avaliação dos demarcadores portugueses, essa capitania era uma das mais importantes de todo o Brasil, tanto pela sua extensão quanto pelas riquezas e por ser fronteira com o Peru. O complexo inventário feito pelo autor sobre as regiões visitadas permite-nos o acesso a elementos muito importantes para a compreensão dos povos indígenas da época, o estudo de suas culturas e seu processo de colonização. No universo de informações e representações construídas a partir das longas expedições realizadas pelos viajantes que aqui estiveram, Alexandre Rodrigues Ferreira faz parte de um grupo de pensadores que descreveram a Amazônia, formulando interpretações de amplo espectro e contribuindo de forma preponderante para a formação do pensamento social na Amazônia. Nesse contexto, ler e analisar Alexandre Rodrigues Ferreira nos remete a uma reflexão antropológica de suas observações relativa ao homem do Novo Mundo. É justamente nesse sentido que vamos compreender a obra do autor; nesse trabalho, especificamente, quando observou e descreveu a classe dos mamíferos observados nos territórios dos rios Amazonas, Negro e Madeira.

\section{Uma reflexão antropológica sobre algumas observações de Alexandre Rodrigues Ferreira}

É sabido que as primeiras observações e descrições sobre os povos do Novo Mundo são provenientes, fundamentalmente, dos relatos dos diversos viajantes que aqui estiveram. A questão inicialmente colocada, na época das expedições, era se aqueles povos recém-descobertos eram seres humanos. Aspectos como religiosidade, aparência física, comportamentos alimentares, inteligência e linguagem eram utilizados para estabelecer comparações entre os povos da América e os da Europa. A existência de um "novo mundo", de outros povos, conturbou e instigou as confrontações e comparações entre a cultura europeia e a dos povos do Novo Mundo. Para Mary Pratt (1999, p. 42), esse fato evidencia "a importante magnitude das mudanças no entendimento que as elites europeias tinham de si mesmas e de suas relações com o resto do mundo". Em outras palavras, o europeu tinha dificuldades

44 Somanlu, ano 9, n. 1, jan./jun. 2009 


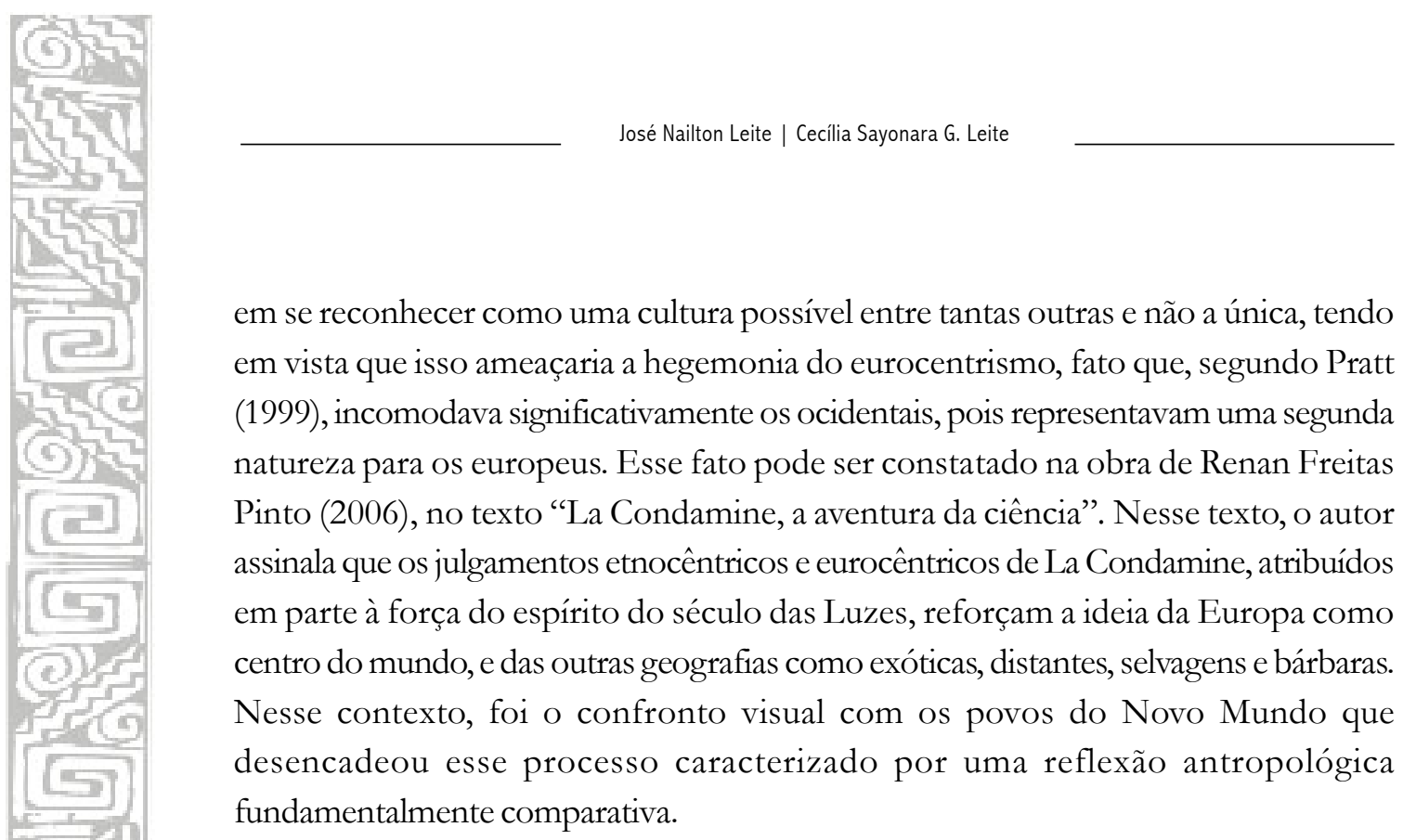

em se reconhecer como uma cultura possível entre tantas outras e não a única, tendo em vista que isso ameaçaria a hegemonia do eurocentrismo, fato que, segundo Pratt (1999), incomodava significativamente os ocidentais, pois representavam uma segunda natureza para os europeus. Esse fato pode ser constatado na obra de Renan Freitas Pinto (2006), no texto "La Condamine, a aventura da ciência". Nesse texto, o autor assinala que os julgamentos etnocêntricos e eurocêntricos de La Condamine, atribuídos em parte à força do espírito do século das Luzes, reforçam a ideia da Europa como centro do mundo, e das outras geografias como exóticas, distantes, selvagens e bárbaras. Nesse contexto, foi o confronto visual com os povos do Novo Mundo que fundamentalmente comparativa.

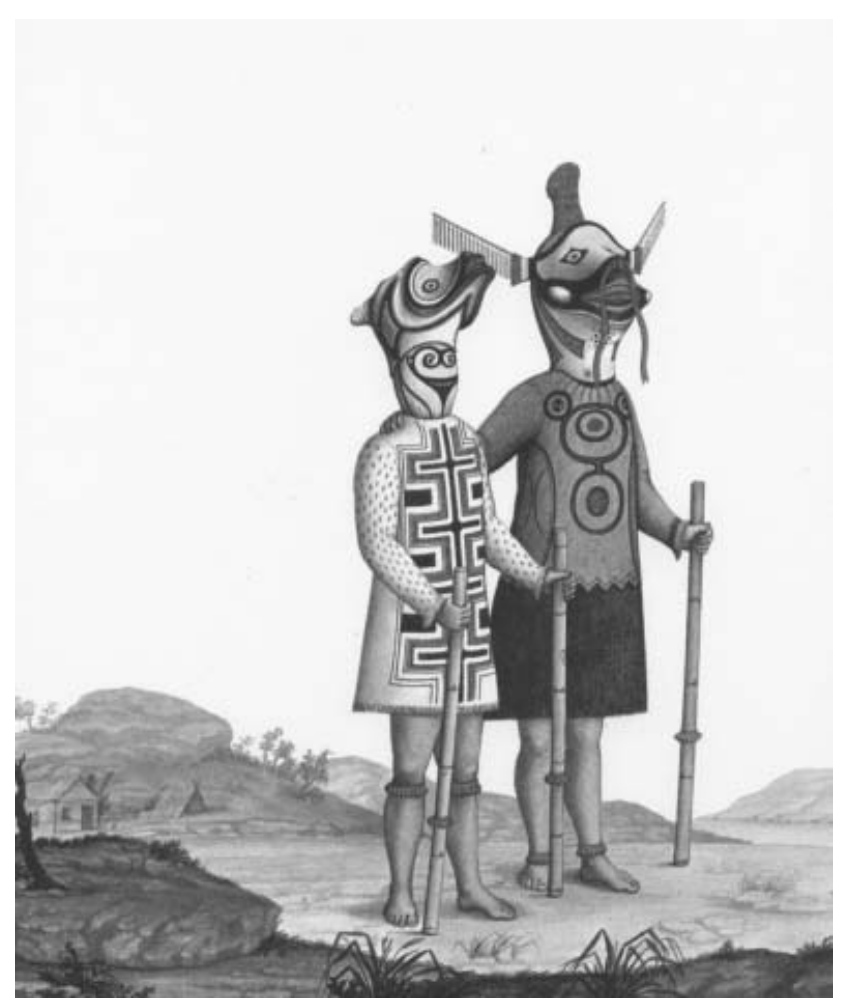

Reprodução

Gravura da expedição de Alexandre Rodrigues Ferreira.

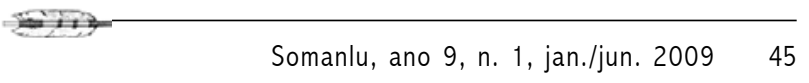


Os viajantes comparavam os povos do Novo Mundo com os europeus, levando em consideração elementos de seus modos de vida, incluindo desde as características físicas até as religiosas. Sem dúvida, as observações e constatações dos viajantes contribuíram de forma marcante para a percepção e a compreensão da gênese da antropologia e da diversidade das sociedades humanas. Laplantine (2000), ao nomear Boas e Malinowski como pais fundadores da Etnografia, demonstra nesses autores a evolução do discurso antropológico desde observações feitas pelos que aqui, inicialmente, estiveram até a sistematização do estudo do homem a partir da antropologia como ciência de fato e de direito. Assim, é possível constatar uma reflexão antropológica nas narrativas de Alexandre Rodrigues Ferreira (ainda que de forma empírica), tendo em vista suas observações não se restringirem à fauna, flora e aos minerais. Elas se estenderam, também, sobre o homem do Novo Mundo.

Em seus escritos, o autor destaca a condição de gentio dos índios, contrapondose à ideia de que esses não eram racionais; enfatiza a presença do exótico e de sua rusticidade. Fala de sua origem, sua semelhança com os bichos, suas crenças e desprezo à riqueza e às coisas materiais, bem como aborda as moradias, seus costumes, suas cerimônias, os vícios da carne e a antropofagia. $\mathrm{O}$ autor propõe as formas, os modos de produção e as técnicas utilizadas para subsistência das nações indígena e colonial. Faz diversas críticas, comentários, análises e sugestões para a exploração racional e colonização da região. Um dos pontos apontados por Ferreira diz respeito ao desenvolvimento da região e das condições de vida dos nativos. Para tal problema, ele propõe a reformulação de alguns pontos da política portuguesa na região. Entre esses propósitos, destacava-se a substituição da exploração das minas e da coleta de drogas do sertão por uma economia de base agrícola e pastoril, fundada em métodos racionais de seleção e aclimação de espécies. (GALVÃO; MOREIRA NETO, 1974, p.14). Naturalista, discípulo de Vandelli, um grande admirador de Lineu, Alexandre Rodrigues Ferreira incluiu nas suas pesquisas, durante a viagem, um estudo detalhado das diversas situações de organização social dos povos da Amazônia à luz da História Natural. No texto intitulado As observaçoes gerais e particulares sobre a classe dos mamiferos observados nos territórios dos três rios, das Amazonas, Negro e da Madeira (produzido em Vila Bela - Mato Grosso, no ano de 1790), é notável o caráter comparativo quando Rodrigues Ferreira, utilizando o Sistema de Linnaeus, descreve os reinos animal e vegetal.

46 Somanlu, ano 9, n. 1, jan./jun. 2009 
Inicialmente, Ferreira compara a máquina animal à máquina vegetal no que concerne à estrutura interna e externa. Nesse momento, afirma que, apesar de os caracteres estruturais dos mamíferos europeus e americanos serem semelhantes, os mamíferos americanos apresentam algumas peculiaridades. Um ponto que nos chama a atenção é a descrição da vida vegetal das Américas:

O que se vê é um país selvagem e sombrio, uma terra bruta e abandonada a si mesma; toda a sua superfície está coberta de infinitas plantas de todas as famílias. Era de se esperar que aqui, semelhante às matas do antigo continente, fossem estas também habitadas por grandes e ferozes animais como elefantes, rinocerontes, tigres e leões (FERREIRA, 1972b, p. $70)$.

Nessa passagem, o autor nos mostra uma tese de debilidade ${ }^{5}$ das Américas já defendida por Buffon quando escreveu sobre a inferioridade das espécies animais na América. Alexandre Rodrigues justifica que, mesmo com toda essa imensidão, os mamíferos do Novo Mundo não se desenvolveram. São pequenos quadrúpedes sem robustez, grandeza e ferocidade quando comparados aos europeus. O autor complementa seu pensamento afirmando que só os vermes e insetos são abundantes e desenvolvidos, parecendo que a natureza despendeu toda a atividade da vida na produção desses. Observa-se aí a sobreposição do critério genético ao geográfico; a natureza americana se apresenta em toda sua imensidão, de um lado, por seu aspecto exuberante e frágil e, do outro, por sua gente tão diferente e caracterizada por tantas singularidades não encontradas nos povos europeus.

Ao descrever a classe dos mamíferos, Ferreira faz um paralelo entre os animais e o homem, particularmente o homem do Novo Mundo. Primeiramente, o autor coloca como principal aspecto para distingui-los o conhecimento de si mesmo. Esse conhecimento é traduzido não somente pelo aspecto fisiológico, mas também pelo patológico, moral, político e teológico. Em seguida, acrescenta que a sabedoria, a docilidade e o ensino formam o caráter essencial de sua espécie. E por fim, afirma que a diversidade da cor, o hábitat e as faculdades corporais indicam variedade entre as espécies. Nesse contexto, Ferreira (1974, p.74) nos dá como exemplo o índio tapuia: "Ele é tão homem como o europeu, o asiático e o africano; em razão da diversidade de sua cor e do País de sua habitação, nós pelo nome de sua própria língua os de- 
nominamos de Tapuia". Isso posto, percebe-se de imediato o choque cultural entre os americanos e os europeus. Alexandre Ferreira diz que o primeiro impacto sofrido por qualquer europeu recém-chegado à América é o encontro com um tapuia: "um homem de uma cor, feições, língua, usos e instituições diversas" (ibidem, p.75). Sem dúvida, a rusticidade dos habitantes do Novo Mundo e o choque visual que chamava a atenção pelo exótico, marcada pelas diferenças fenotípicas verificadas entre os povos recém-descobertos e os europeus, são fatores determinantes para uma reflexão antropológica, em cujo cerne tornam-se evidentes os confrontos culturais gerados em razão de aspectos ideológicos, religiosos e comportamentais, bem como a contribuição significativa para a criação de estereótipos a partir de diferentes categorias sociais, tais como os padrões e valores europeus.

Por sermos europeus somos distinguidos hoje entre os índios domesticados pelo nome de Cariba suaivara ou Branco europeu. Aos pretos chamam de Tapaiuna- Tapuia preto. Os Tapuias não têm outras diferenças senão as que são acidentais ao ser humano. Diversificam na cor a qual, como se verá adiante, é mais ou menos acastanhada, segundo alturas em que habitam; segundo o estado físico de seus corpos ou seja: são ou enfermos e segundo a vida que levam, mais ou menos exposta às impressões do tempo. Diversificam na língua porque não é como a nossa e entre eles, nem todos falam a mesma, sendo tantas as suas línguas quantas as diversas tribos de gentios que habitam as ilhas e o continente da América. Diversificam na energia e no exercício das potências e faculdades intelectuais. Apesar de seu espírito não ser tão vivo e ativo como os pretos, também selvagens, são capazes de ensinar aquilo que os desperta e os faça refletir o que lhe traga melhorias. [...] O Tapuia representa um homem dócil, tranquilo e tratável. Mas examinado de perto, logo deixa transparecer um ar selvagem, de desconfiança e sombrio (ibidem, p.74-5).

Insensivelmente movido pelo mesmo raciocínio, Buffon estende ao selvagem americano o juízo negativo quando cria um nexo singular entre a ausência de animais ferozes e um selvagem impotente: "Frio é o selvagem, fria é a serpente" (apud GERBI, 1996). Notadamente, Buffon considerava o homem americano como

48 Somanlu, ano 9, n. 1, jan./jun. 2009 


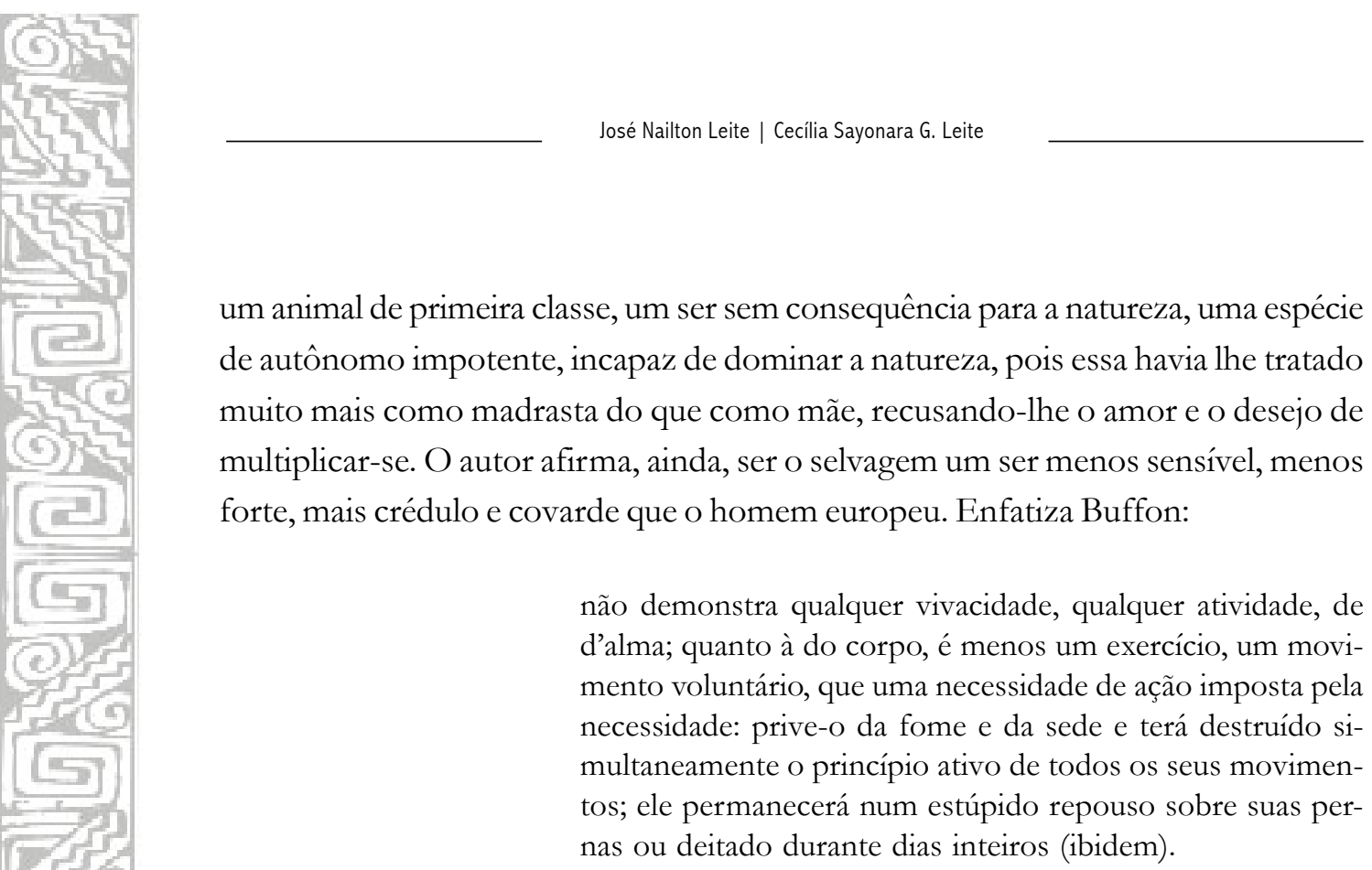

Pode-se perceber nessa passagem o estigma da "preguiça" fortemente representado. O homem americano foi incapaz de reverter as forças da natureza em seu benefício. Em vez de colaborar para o desenvolvimento dessa, preferiu permanecer submisso ao seu controle. Vemo-nos diante de um discurso dual e antagônico entre a História natural do século XVIII e o Preservacionismo pós-moderno. Para a primeira, era imprescindível a intervenção do homem para ordenar a natureza; para o segundo, é justamente essa mesma intervenção que destrói a natureza. Isso significa dizer que, no contexto do século das Luzes, a organização da natureza dependia fundamentalmente da presença do homem; sem ele, a grandiosidade da natureza permaneceria hostil e sem sentido. Paradoxalmente, para o Preservacionismo pós-moderno, a presença do homem é nociva à natureza, pois o que se observa é a destruição dessa, gradativamente, num caminho sem volta, já que as discussões acerca do tema (preservação da natureza) são muito mais teóricas do que práticas e concretas. A alusão a esse discurso aqui apresentada tem a finalidade de abrir um parêntese e chamar a atenção do leitor para uma reflexão sobre a relação homem/ natureza que, historicamente, tem envolvido a Região Amazônica num misto de mito e realidade de uma natureza intocada.

Isso pode ser constatado na obra de Neide Gondim (1994) A Invenção da Amazônia. A autora afirma que "as potencialidades imaginárias que os autores de ficção pensam existir na Amazônia ainda guardam o vigor dos tempos primeiros dos 


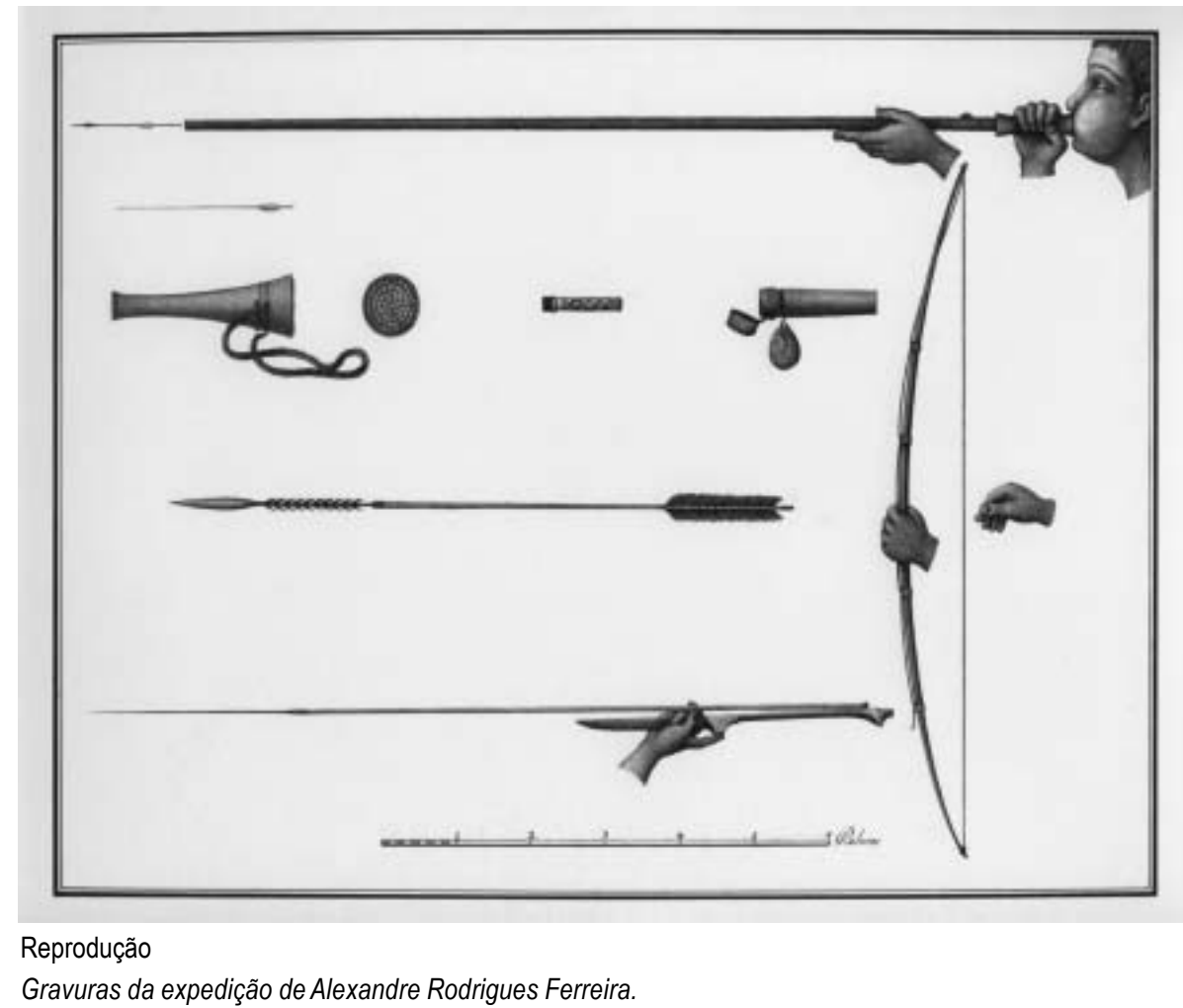

navegadores de águas turvas e cristalinas do rio das Amazonas e de seus tributários no bordado de suas estradas líquidas" (ibidem, p. 271). Destacam-se dois argumentos marcantes no contexto cultural/ideológico e ao mesmo tempo importantes para a compreensão da origem antropológica e da diversidade das sociedades humanas: a figura do índio domesticado e a do índio selvagem, bem caracterizada por Alexandre Rodrigues Ferreira. A figura do selvagem representava a linha de pensamento que via o homem do Novo Mundo como um animal, desprovido de racionalidade, convivendo sem nenhuma regra social, sem história e sem futuro, vivendo como feras do mato. A outra representação, do domesticado, colocava o índio, homem do Novo Mundo, como um ser ingênuo, servidor, desprovido de ambição e de apego às riquezas ou coisas materiais, movido apenas pelos impulsos fisiológicos, vivendo de forma tranquila e harmoniosa com os visitantes do Velho Mundo.

Tais tendências propõem o surgimento do conhecimento antropológico esboçado por viajantes, navegantes e missionários. Pois, segundo Laplantine (2000, p.

50 Somanlu, ano 9, n. 1, jan./jun. 2009 


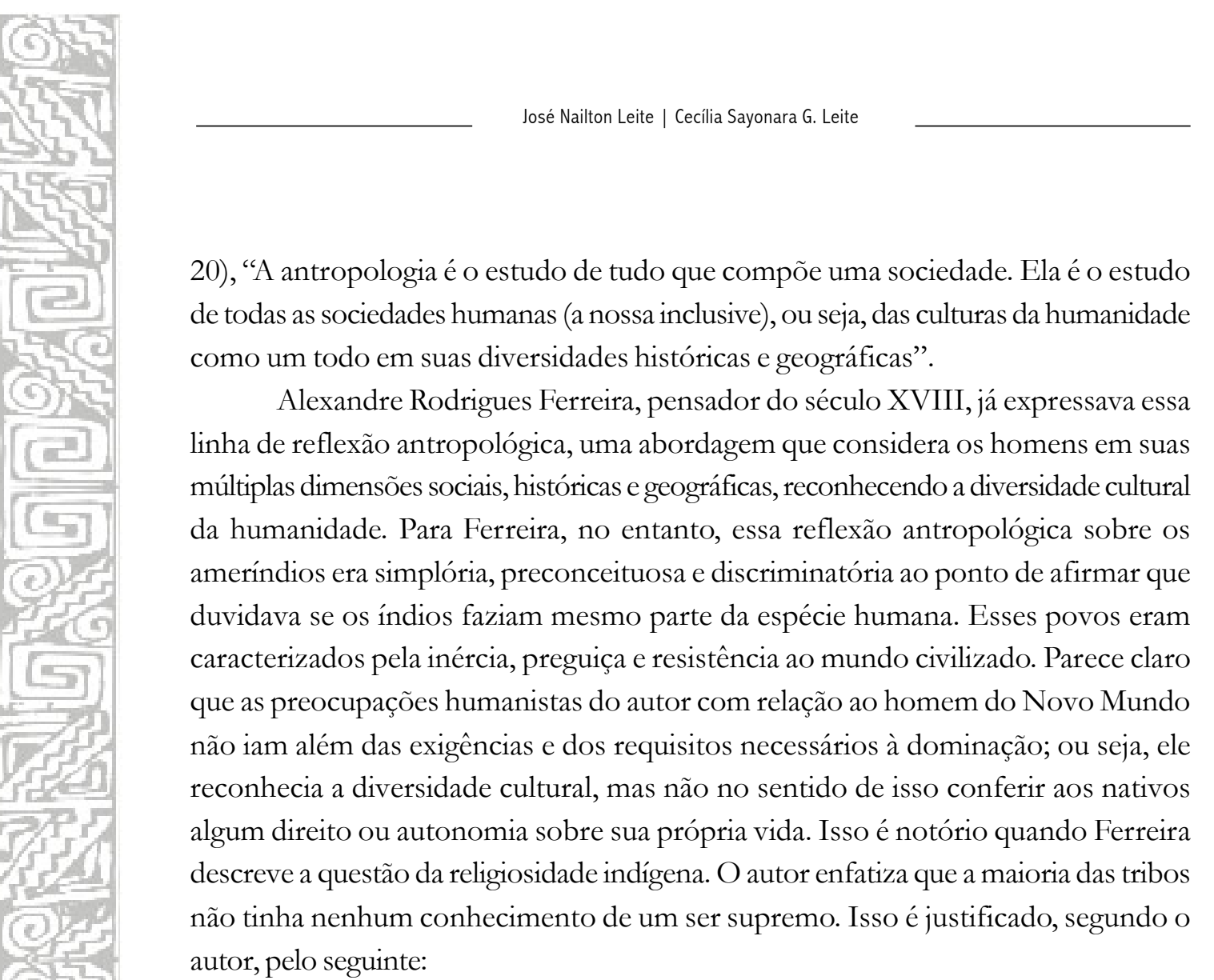

é justamente na infância que o caráter religioso deve ser construído socialmente em cada indivíduo, porém as potências intelectuais são tão débeis no índio que o tornam incapaz de distinguir-se dos animais: Nem a ordem, nem a beleza do universo fazem a menor impressão aos seus sentidos. Na sua língua não há uma só expressão que designe a divindade. Vive, porém, não faz mais do que vegetar. Olha, porém não reflete; aprende, mas não raciocina. Pelo que se vê, os seus espíritos não se acham exercitados pela filosofia nem iluminados pela revelação. Seria absurdo pretender que seja capaz de reconhecer a existência de um ser invisível, quem não reflete nem discorre. [...] aos selvagens estúpidos do Novo Mundo que andam errantes pelos montes, sem lei, nem culto, sem templos e sacrifícios, são uns homens que apenas conservam a figura de homens, de razão obscurecida, embrutecida e sepultada na matéria. [...] Nós não fazemos juízo das faculdades do corpo humano pelos mudos, surdos, cegos e nem coxos e querem que o façamos dos ditames da linguagem humana por uns homens toscos, estúpidos e idiotas? (FERREIRA, 1974, p. 94-5) 
Os europeus não consideravam lógicas as ideias e os pensamentos dos povos do Novo Mundo; portanto, não fazia sentido acreditar neles ou fazer juízo disso. Jamais essas desrazões poderiam quebrar a ordem de um conjunto de verdades reconhecido por todos os povos civilizados. Seria necessário ao bom civilizado, o missionário, trazê-los para a luz, fazê-los acreditar em Deus, libertando-os da idolatria e de outros costumes bárbaros. Mais uma forma de rejeitar e reconhecer a diversidade sociocultural da humanidade. Isso era comprovado, conforme o autor, nas constantes demonstrações de docilidade, nos bons exemplos, na caridade e no exercício da virtude praticada pelos missionários. Foi exatamente isso que tocou os selvagens, vencendo a sua desconfiança e ferocidade. Em relação à constituição moral, Ferreira afirma que faltava nos americanos a ternura e o afeto que as mulheres dedicavam aos seus maridos entre os povos civilizados. "A tapuia na realidade não é mulher e sim, escrava de seu marido" (ibidem, p. 96). Não existiam cuidados com o controle familiar, não havia lei nem religião que moderasse o apetite do coito. $\mathrm{O}$ amor dos pais pelos filhos durava tanto quanto o de qualquer outro animal. Não se observava o pai aconselhar ou orientar um filho. Nas palhoças viviam todos irmanamente juntos. $\mathrm{O}$ que entre os civilizados só acontecia com muita privacidade, eles praticavam uns ao lado dos outros. Além disso, a indiferença na relação entre pais e filhos enfraquecia a instituição familiar, pois era uma relação sem união e amor, fatores imprescindíveis na formação do caráter de uma família entre os povos civilizados. Quando trata da constituição política, o autor explica que a noção de nação era completamente diferente do que ocorria na Europa. Os americanos chamavam de nação pequenas corporações com aproximadamente 300, 400 e 600 indivíduos; os quais ocupavam áreas muitas vezes maiores que os maiores reinos da Europa.

Organizavam-se às margens dos rios dividindo o mesmo espaço acomodado em aldeias. Cada maloca era governada por um membro principal, não havia um só que governasse todos. Cada um fazia justiça à sua maneira, cada um tendo o direito de vingança quando fosse necessário. Observam-se, durante toda a narrativa, a inferioridade e o atraso na organização social dos povos do Novo Mundo, em comparação com as sociedades ditas civilizadas.

Em relação à política indígena, Ferreira teve grande participação na formulação no conjunto de normas, segundo os valores e interesses da colônia, que comporiam essa política. Essa época coincide com a queda de Pombal e o regresso no

52 Somanlu, ano 9, n. 1, jan./jun. 2009 
O processo de submissão do índio aos interesses dominantes da sociedade nacional cumpriu-se integralmente, culminando com a sanção oficial de seu estado de dependência compulsória através dos mencionados atos administrativos e legais que, em 1798, estabelecem as bases da política indigenista de D. João VI. (ibidem, p. 20)

\section{Considerações finais}

Diante do exposto, pode-se concluir que a obra de Alexandre Rodrigues Ferreira se constitui em um valioso inventário sobre a Amazônia no século XVIII. O acesso a essa fonte permite o conhecimento de elementos imprescindíveis à compreensão da formação do pensamento social amazônico. Para Freitas Pinto (2006, p. 22), é justamente a partir da leitura sistemática do texto de Ferreira e de outros viajantes que aqui estiveram que se torna "possível não apenas a reconstrução do pensamento social sobre a Amazônia, mas a revelação e descoberta de elementos mais significativos da formação sociocultural dessa parte do Brasil”". 
Nesse contexto, a obra de Rodrigues Ferreira, mesmo escrita e arquivada em condições adversas, e ainda que influenciada pelas possíveis lacunas em sua formação intelectual e científica, nos deixa um volume inestimável de informações sobre a Amazônia, evidencia as limitações do trabalho científico na Amazônia, tendo em vista o padrão limitado e decadente da política colonial de Portugal; além do mais, a interpretação de Ferreira sobre os povos do Novo Mundo foi relevante para a compreensão do pensamento científico sobre esses povos e o meio natural do qual faziam parte.

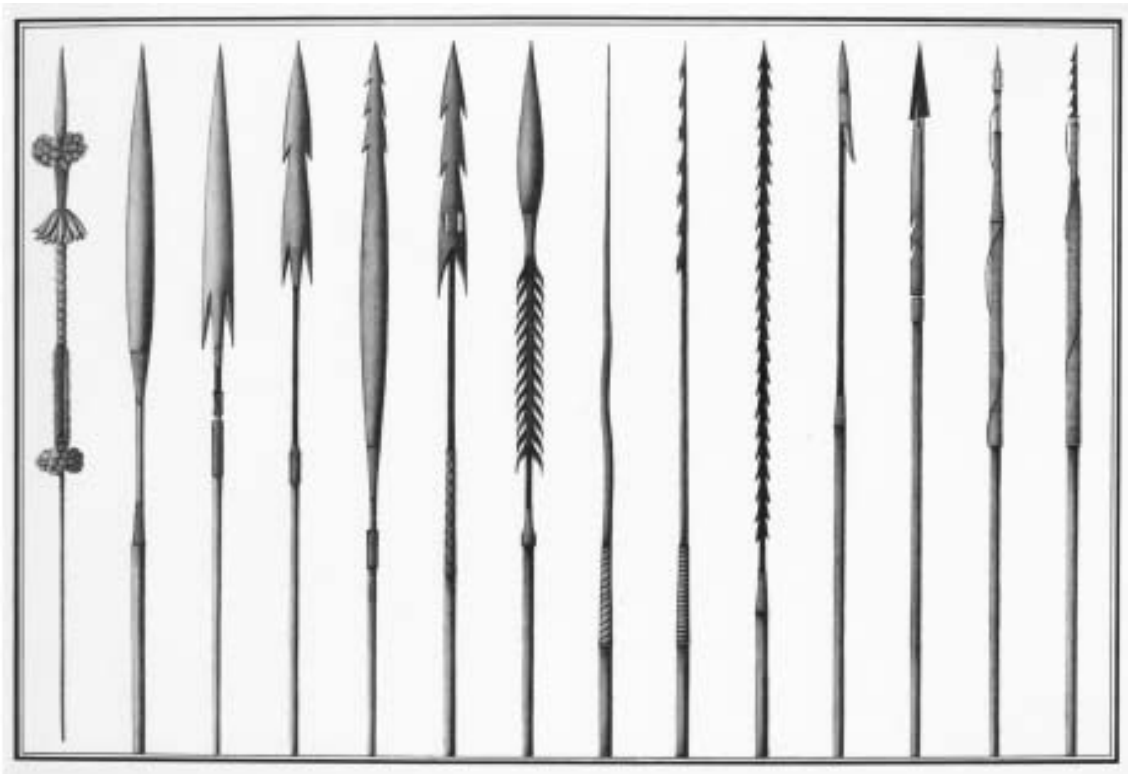

Reprodução

Gravuras da expedição de Alexandre Rodrigues Ferreira.

Dessa forma, a obra de Alexandre Rodrigues Ferreira, ao relatar a Amazônia do século XVIII e contribuir de modo significativo para a formação do pensamento social na região, continua atual em muitos aspectos, tais como o fato de a colonização da Região Amazônica mesmo quatro séculos depois ainda se perpetuar; a ideia de destruição da natureza e extinção de plantas e animais não fazia parte das preocupações de Ferreira e, até hoje, parece não fazer parte das preocupações das autoridades e da própria humanidade, além do discurso retórico da "alta-sustentabilidade"; além

54 Somanlu, ano 9, n. 1, jan./jun. 2009 


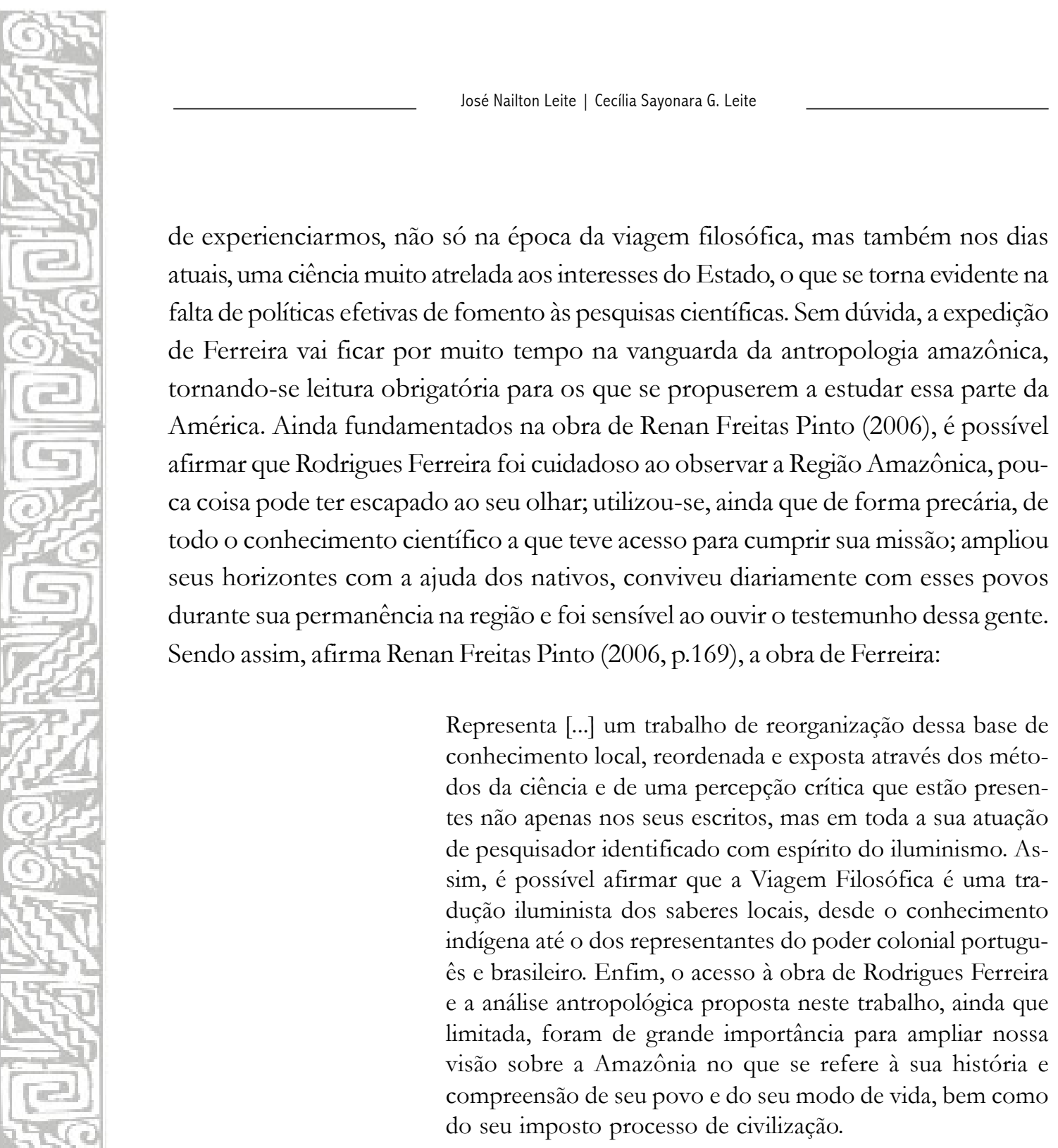

de experienciarmos, não só na época da viagem filosófica, mas também nos dias atuais, uma ciência muito atrelada aos interesses do Estado, o que se torna evidente na falta de políticas efetivas de fomento às pesquisas científicas. Sem dúvida, a expedição de Ferreira vai ficar por muito tempo na vanguarda da antropologia amazônica, tornando-se leitura obrigatória para os que se propuserem a estudar essa parte da América. Ainda fundamentados na obra de Renan Freitas Pinto (2006), é possível afirmar que Rodrigues Ferreira foi cuidadoso ao observar a Região Amazônica, pouca coisa pode ter escapado ao seu olhar; utilizou-se, ainda que de forma precária, de todo o conhecimento científico a que teve acesso para cumprir sua missão; ampliou seus horizontes com a ajuda dos nativos, conviveu diariamente com esses povos durante sua permanência na região e foi sensível ao ouvir o testemunho dessa gente.

Representa [...] um trabalho de reorganização dessa base de conhecimento local, reordenada e exposta através dos métodos da ciência e de uma percepção crítica que estão presentes não apenas nos seus escritos, mas em toda a sua atuação de pesquisador identificado com espírito do iluminismo. Assim, é possível afirmar que a Viagem Filosófica é uma tradução iluminista dos saberes locais, desde o conhecimento ndigena até o dos representantes do poder colonial portugurigues Ferreira alho, ainda que nossa compreensão de seu povo e do seu modo de vida, bem como do seu imposto processo de civilização.

\section{Notas}

1 Domingos Vandelli foi professor de Alexandre Rodrigues, responsável pelas reformas na Universidade de Coimbra e idealizador desse tipo de expedição (COSTA, 2001). 
2 Um tipo de expedição científica, coordenada por naturalistas, com o objetivo de explorar as riquezas e inventariar os recursos naturais no interior do território colonial, particularmente do Brasil. Filosófica porque se propunha a observar e interpretar a natureza nos seus diversos domínios.

3 Denominação dada aos desenhistas que acompanharam Alexandre Rodrigues Ferreira na viagem filosófica. Eles eram responsáveis por registrar em um conjunto de aquarelas o material colhido durante a expedição.

4 Chamamos a atenção para a observação feita pelo autor ao descrever o índio como selvagem ou domesticado, comparando-o aos animais e atribuindo-lhe uma natureza hostil.

5 Tese que nasceu com Buffon em meados do século XVIII. Buffon a considerava uma de suas maiores descobertas e da qual se orgulhava muito (GERBI, 1996)

\section{Referências}

COSTA, M. de F. Alexandre Rodrigues Ferreira e a capitania de Mato Grosso: imagens do interior. História, Ciência, Saúde - Manguinhos, Rio de Janeiro, v. VIII, suplemento, p. 993-1014, 2001.

FERREIRA, A. R. Viagem filosófica pelas capitanias do Grão-Pará, Rio Negro, Mato Grosso e Cuiabá. Rio de Janeiro: Conselho Federal de Cultura, 1971. 2v.

- Viagem filosófica pelas capitanias do Grão-Pará, Rio Negro, Mato Grosso e Cuiabá. Memórias Zoologia e Botânica. Rio de Janeiro: Conselho Federal de Cultura, 1972a.

- Viagem filosófica pelas capitanias do Grão-Pará, Rio Negro, Mato Grosso e Cuiabá. Observações gerais e particulares sobre a classe dos mamíferos observados nos territórios dos três rios, Amazonas, Negro e Madeira. Memórias. Rio de Janeiro: Conselho Federal de Cultura, 1972b. p. 67-204. v. 2.

- Viagem filosófica pelas capitanias do Grão-Pará, Rio Negro, Mato Grosso e Cuiabá. Memórias Antropologia. Rio de Janeiro: Conselho Federal de Cultura, 1974 .

GALVÃO, E.; MOREIRA, N. Introdução. In: FERREIRA, A. R. Viagem filosóficapelas capitanias do Grão-Pará, Rio Negro, Mato Grosso e Cuiabá. Rio de Janeiro: Conselho Federal de Cultura, 1974.

56 Somanlu, ano 9, n. 1, jan./jun. 2009 


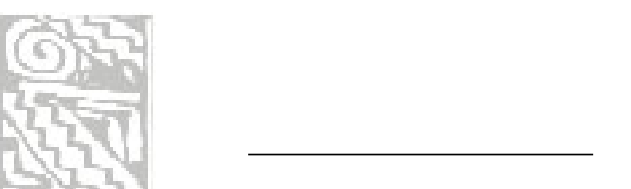

José Nailton Leite | Cecília Sayonara G. Leite

GERBI, A. O Novo Mundo: história de uma polêmica 1750-1900. São Paulo: Cia. Das Letras, 1996.

GONDIM, N. A invenção da Amazônia. São Paulo: Marco Zero, 1994.

LAPLANTINE, F. Aprender antropologia. Tradução de Marie-Agnés Chauvel. São Paulo: Brasiliense, 2000.

PINTO, R. F. Viagem das ideias. Manaus: Valer, 2006.

PRATT, M. L. Os olhos do império: relatos de viagem e transculturação. Bauru: Edusc, 1999.

PRESTES, M. E. B. A investigação da natureza no Brasil colônia. São Paulo: Annablume, Fapesp, 2000. 